\title{
Impact of ocean Currents on wind stress in the Tropical Indian Ocean
}

${ }^{1}$ Neethu Chacko, ${ }^{2,3} \mathrm{M}$ M Ali

\author{
${ }^{1}$ Regional Remote Sensing Centre-East \\ National Remote Sensing centre, ISRO \\ BG2, Action Area1B, \\ Kolkata, India \\ ${ }^{2}$ Centre for Ocean-Atmospheric Prediction Studies \\ Florida State University, USA \\ ${ }^{3}$ Andhra Pradesh State Disaster Management Authority \\ India
}

Corresponding author: MM Ali

Email: mmali110@gmail.com; mmali@coaps.fsu.edu

\begin{abstract}
:
This study examines the effect of surface currents on the bulk algorithm calculation of wind stress estimated using the scatterometer data during 2007-2020 in the Indian Ocean. In the study region as a whole the wind stress decreased by $5.4 \%$ by including currents into the wind stress equation. The most significant reduction in the wind stress is found along the most energetic regions with strong currents such as Somali Current, Equatorial Jets and Aghulhas retroflection. A highest reduction of $11.5 \%$ is observed along the equator where the Equatorial Jets prevail. A sensitivity analysis has been carried out for the study region and for different seasons to assess the relative impact of winds and currents in the estimation of wind stress by changing the winds while keeping the currents constants and vice versa. The inclusion of currents decreased the wind stress and this decrease is prominent when the currents are stronger. This study showed that equatorial Indian Ocean is the most sensitive region where the current can impact on wind stress estimation. The results showed that uncertainties in the wind stress estimations are quite large at regional levels and hence better representation of wind stress incorporating ocean currents should be considered in the ocean/climatic models for accurate air-sea interaction studies.
\end{abstract}

Key words: scatterometer, wind stress, surface currents, current coupling, Indian Ocean 


\section{Introduction}

Winds play an instrumental role in driving the surface currents and also in the air-sea interaction processes. Accurate measurements of wind stress are required to understand the air-sea interaction and other climate variability. Most of the air-sea interaction processes are determined using wind stress which is a measure of transfer of momentum due to the relative motion between the ocean and atmosphere. Wind stress also exerts surface oceanic circulation which in turn results in the redistribution of heat and other properties. Wind stress is calculated according to the bulkaerodynamic formula as,

$$
\tau=\rho_{a} C_{d}\left(U_{w}\right) *\left|U_{w}\right|
$$

where, $\rho_{a}$ the density of air, $C_{d}$ the drag coefficient and $U_{w}$ the wind velocity respectively. Global ocean winds are measured using scatterometers which measure radar backscatter from the ocean surface. The relative motion between the atmospheric winds and ocean currents modulate the amount of backscatter even though it is primarily determined by the magnitude of winds (Plagge et al., 2012). The wind speeds measured by scatterometers are actually higher or lower depending on the relative direction of the winds with the existing ocean currents. Kelly et al., (2001) reported that in the Pacific Ocean the differences between the scatterometer winds and anemometer winds measured by buoy moorings are explained by the surface currents measured by the buoys. As the relative ocean currents clearly impact the wind measurements, the effect due to currents should be accounted while computing the air-sea coupling processes. Hence, the relative motion between the ocean and atmosphere should be included in computing the momentum fluxes, in particular the wind stress. Earlier studies have pointed out the importance of including relative motion in the assessment of air-sea interactions. Paconowski, 1987 showed that when the effects of currents are included in the simulation of the tropical Atlantic, the equatorial 
currents reduced by $30 \%$ which also had an impact on the upwelling and sea surface temperature variability. A basin wide reduction of wind stress by $\sim 15 \%$ is reported by Dave and Thompson, 2006 in the northern Pacific Ocean by incorporating currents in the wind stress computation. Similar study by Luo et al., (2005) found that improved estimates of sea surface temperature is obtained when the wind stress is computed with relative motion between the ocean and the atmosphere. Kloe et al., 2017 emphasized the usage of stress-equivalent surface wind speeds from scatterometers than using direct neutral-winds by incorporating the local air-mass. Ali et al., 2013 and Ali et al., 2016 estimated wind stress directly from the scatterometer and altimeter measurements of surface radar backscatter. They found out that the wind stress estimated from this approach is better than those estimated from the conventional approach using winds at $10 \mathrm{~m}$ height. These approaches assumes that the atmosphere is neutrally stable and there are no surface currents which is not the real scenario. They, however, did not include currents in the estimations. So the inclusion of surface currents into the bulk formula for wind stress modifies equation (1) to

$$
\tau=\rho_{a} C_{d}\left(U_{w}-U_{o}\right) *\left|U_{w}-U_{o}\right|
$$

Where, $\mathrm{U}_{\mathrm{w}}-\mathrm{U}_{\mathrm{o}}$ is the difference between the surface wind $\left(\mathrm{U}_{\mathrm{w}}\right)$ and ocean current $\left(\mathrm{U}_{\mathrm{o}}\right)$. Often the inclusion of surface currents in the wind stress is neglected because wind speeds are much higher than surface currents. However, in the oceanic regions where surface currents are stronger, the impact of it on the wind stress estimates can be higher. This current-wind interaction which is termed as "relative wind stress" [Song et al., 2020] is capable of modulating mesoscale processes, vertical upwelling and momentum transfer. Duhaut and Straub, 2006 showed that the currents through the modification of wind stress significantly reduces wind power input into the ocean. Seo et al., 2019 examined the impact of current- wind interaction on the upper ocean stratifications and 
geostrophic circulation in the Bay of Bengal using a regional coupled model simulation. They found that the current inclusion in the wind stress estimation significantly modulated the geostrophic current field and increased the stratification. The impact of currents on air-sea momentum and heat flux exchanges in the Gulf stream is reported by Shi and Bourassa, 2019 using a numerical model. The impact of sea surface temperature on the scatterometer-derived wind speed and wind stress is assessed by O' Neil et al., 2012. Chelton et al. 2004 analysed QuikSCAT Satellite measurements and observed persistent small-scale features in the curl and divergence in ocean wind stress. They also reported clear curl field patterns in the Gulf Stream. This study, however, emphasises the impact of currents alone on the estimation of satellite derived wind stress in the Indian Ocean.

Indian Ocean surface currents are unique because of its seasonally reversing nature in response to the reversing monsoonal winds [Sankar et al., 2002; Shenoi et al., 1999; Schott and McCreary, 2001]. The major currents in the Indian Ocean are the Southwestern Monsoon Current, the Northeastern Monsoon Current, the Somali Current, the East India Coastal Current, the West India Coastal Current and the Equatorial Jets. The Summer Monsoon Current flows eastward during the summer season (June-September) and the Winter Monsoon Current flows westward during the winter monsoon (December-February). The Somali currents are very strong western boundary currents which flows northwards during southwest monsoon and southward during northeast monsoon (Schott,1993). Swallow and Bruce, (1966) reported that the Somali Current can reach up to $2-3 \mathrm{~m} / \mathrm{s}$ in the summer monsoon season. The Equatorial jets however, flows eastward along the equator during the transition months (April-May and October-November) (Wyrtki, 1973). Thus, studying the impact of currents on the wind stress estimation is apt.

In this context, we try to examine the impact of currents on the wind stress estimation in the tropical Indian Ocean. Previous studies assessed the impact of currents on wind stress using 
model simulations (Dave and Thompson, 2006; Seo, 2016; Seo, 2017). Seo et al., 2019 using regional coupled model simulations tried to assess the relative wind effect in the Bay of Bengal. However, no study proved the relative difference of the current impact on the wind stress over the different current systems in the Indian Ocean. Here, we try to assess the impact of currents on wind stress estimations in the tropical Indian Ocean using scatterometer observations. We compare the wind stress estimations through the bulk formula for wind stress with and without the surface currents and figure out the variability of the wind stress in the major current systems of the Indian Ocean.

\section{Materials and Methods}

\subsection{Data}

In this study, we utilize scatterometer winds and satellite derived surface currents to assess the impact of currents on wind stress estimation in the tropical Indian Ocean. Wind speeds from the Advanced Scatterometer (ASCAT) on-board Metop-A and Metop-B of the European Organization are utilized in this work. The study region includes the tropical Indian Ocean bounded by $30^{\circ} \mathrm{E}-$ $120^{\circ} \mathrm{E}$ longitudes and $30^{\circ}-30^{\circ} \mathrm{N}$ latitudes. The daily gridded ASCAT winds with $0.25^{\circ} \mathrm{X} 0.25^{\circ}$ resolution for the period 2007 to 2020 are used. Near-surface currents (averaged over the top $30 \mathrm{~m}$ ) estimated by Ocean Surface Current Analysis Real-time (OSCAR, Bonjean and Lagerloef, 2002) during the same period are used in the study. OSCAR currents are available with $1 / 3^{\circ} \times 1 / 3^{\circ}$ resolution with 5 days temporal resolution. The OSCAR product is a direct computation of global surface currents using satellite sea surface height, wind, and temperature. OSCAR currents are calculated using a quasi-steady geostrophic model together with an eddy-viscosity based winddriven ageostrophic component and a thermal wind adjustment. The model calculates a surface 
current averaged over the top $30 \mathrm{~m}$ of the upper ocean. The ASCAT surface winds are re-gridded to match the spatial and temporal resolution of OSCAR surface currents for computing the wind stress.

\subsection{Methods}

To quantify the effect of currents on the wind stress in Indian Ocean, wind stress is computed with and without the currents in the wind stress equations. The wind stress computed without and with the surface currents following equation (1) and equation (2) are referred as $\tau_{\mathrm{no}-\mathrm{Cur}}$ and $\tau_{\mathrm{Cur}}$ estimations, respectively. To assess the relative difference between the strengths of winds and currents in inducing the differences in wind stress, two sets of experiments are conducted by varying the currents and wind speeds. In the first experiment, the wind speeds are increased by keeping the current speeds as such (EXP1). Wind stress is estimated with and without currents by increasing the wind speeds by 5\% and $10 \%$. These experiments are referred as EXP1_W5 and EXP1_W10 respectively. In the second experiment, the current speeds are altered without changing the wind speeds (EXP2). Wind stress is estimated by increasing current speeds by $5 \%$ and $10 \%$. These experiments are referred as EXP2_C5 and EXP2_C10 respectively. The estimation without altering either the winds or the currents is referred as NOEXP. In all the sets of experiments, the $\tau_{\text {no-Cur }}$ and $\tau_{\text {Cur }}$ are computed and the difference between the two are analyzed.

\section{Results and Discussions}

\subsection{Annual Impact}

The annual means of the wind stress with $\left(\tau_{\text {Cur }}\right)$ and without $\left(\tau_{\text {no-Cur }}\right)$ currents in the Indian Ocean and the difference between the two are presented in Figure 1. The striking feature in the 
wind stress pattern in both the estimations is over the south-east trade winds which occurs south of $10^{\circ} \mathrm{S}$ and persist throughout the year in the Indian Ocean (Schott and McCreary, 2001). An overall basin wide reduction in the wind stress can be seen by including currents into the wind stress equation (Figure 1c). 


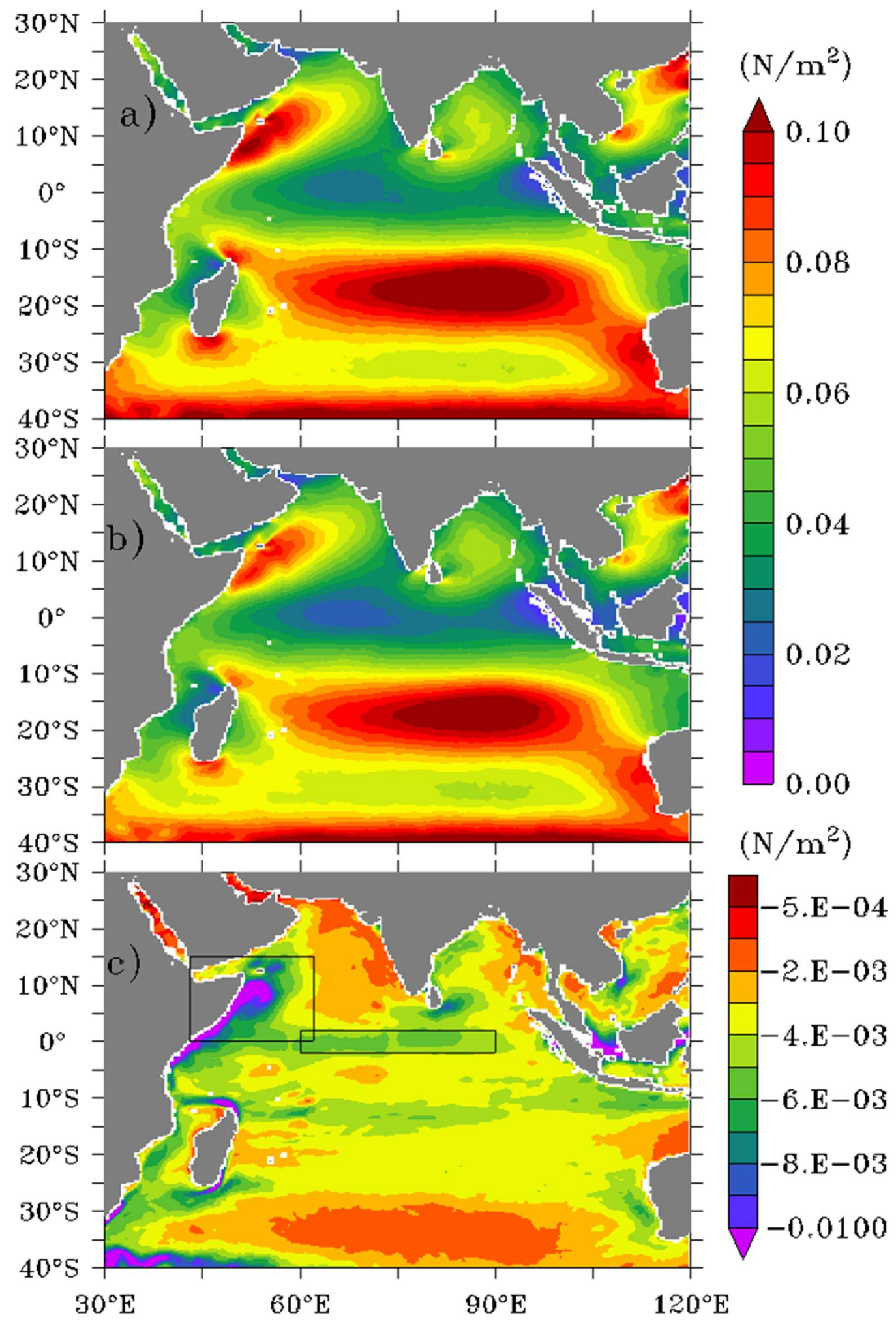

Figure 1. Wind stress $\left(\mathrm{N} / \mathrm{m}^{2}\right)$ estimated (b) without currents, (b) with currents and (c) difference between the two wind stresses $(b-a)$. The regions off Somali Coast and equatorial Indian Ocean are shown as boxes in Fig. (c). 
Besides a few small-scale features being clearly visible, the notable differences between the two fields ( $\tau_{\text {no-Cur }}$ and $\tau_{\text {Cur }}$ ) are (i) along the region off Somali coast between $0-15{ }^{\circ} \mathrm{N}$ latitudes to the east of $60{ }^{\circ} \mathrm{E}$ longitude, (ii) a narrow band of region between $30{ }^{\circ} \mathrm{E}-60^{\circ} \mathrm{E}$ and south of $35^{\circ} \mathrm{S}$, which is the regime of Aghulhas current, (iii) a band of \pm 4 degrees of the equator between $60^{\circ} \mathrm{E}-90^{\circ} \mathrm{E}$ and (iv) the region off the eastern coast of India. The difference is negative in the entire study region indicating that stress without currents is more than the stress without current. However, the stress differences are found to be negligible in the Arabian Sea and in the Southern Ocean between $40^{\circ} \mathrm{S}$ $30^{\circ} \mathrm{S}$ latitudes.

\subsection{Zonal and regional Impact}

The zonal average of the wind stress difference (Figure 2) shows that highest deviation occurs along the equatorial Indian Ocean around $2^{\circ} \mathrm{N}$. This large difference at $2^{\circ} \mathrm{N}$ is because the large stress difference along $2^{\circ} \mathrm{N}$ as shown in Figure 1c. Since the currents are more in this region (Shenoi et al., 1999; Schott and McCreary, 2001), the difference is also more. Table 1 summarizes

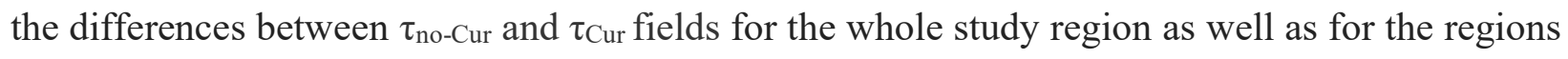
of Somali current and Equatorial Jets. It is noted that by including surface currents into the wind stress computation, the basin-wise averaged wind stress decreased by $5.8 \%$. Notable differences in the percentage reduction of wind stress exist when surface currents are accounted for Somali current region (-9.56\%) and Equatorial Jet region (-15.93\%). 


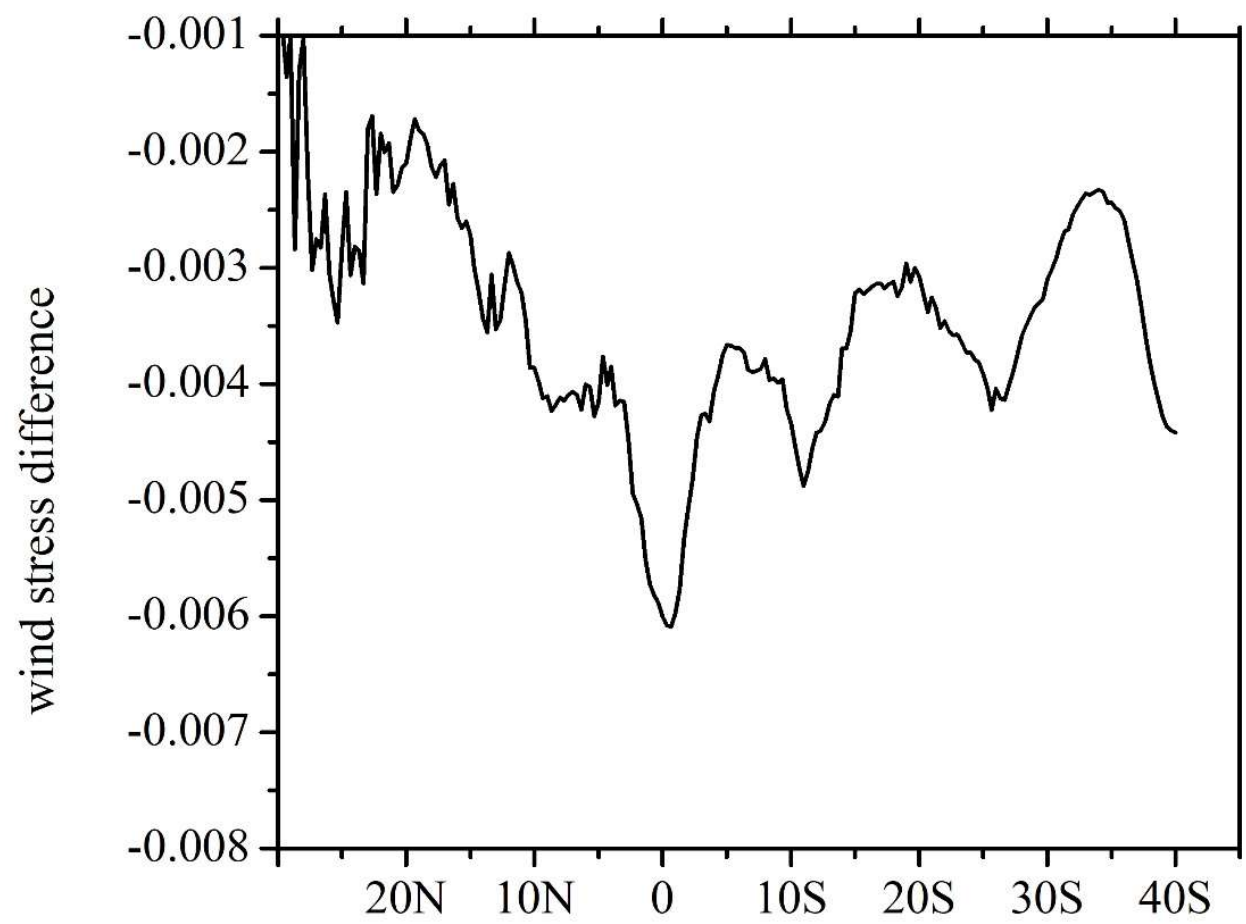

Figure 2 Zonal average of wind stress difference $\left(\tau_{\text {Cur- }} \tau_{\mathrm{no}-\mathrm{Cur}} ; \mathrm{N} / \mathrm{m}^{2}\right)$ in the tropical Indian Ocean

Table 1. Area averaged wind stress during 2007-2020

\begin{tabular}{|l|l|l|l|l|}
\hline & $\tau_{\text {no-Cur }}\left(\mathbf{N} / \mathbf{m}^{2}\right)$ & $\tau_{\text {Cur }}\left(\mathbf{N} / \mathbf{m}^{2}\right)$ & $\begin{array}{l}\tau_{\text {Cur }}-\tau_{\text {no-Cur }} \\
\left(\mathbf{N} / \mathbf{m}^{2}\right)\end{array}$ & $\%$ difference \\
\hline Basin Average & 0.06448 & 0.06073 & -0.00282 & $-5.81 \%$ \\
\hline $\begin{array}{l}\text { Somali Current } \\
\left(43^{\circ} \mathrm{E}-64^{\circ} \mathrm{E} ; 0-\right. \\
\left.15^{\circ} \mathrm{N}\right) \text { region }\end{array}$ & 0.06264 & 0.05665 & -0.00599 & $-9.56 \%$ \\
\hline $\begin{array}{l}\text { Equatorial Jet } \\
\left(60^{\circ} \mathrm{E}-90^{\circ} \mathrm{E} ; 2^{\circ} \mathrm{S}-\right.\end{array}$ & 0.03145 & 0.02644 & -0.00501 & $-15.93 \%$ \\
$\left.2^{\circ} \mathrm{N}\right)$ region
\end{tabular}




\subsection{Monthly and Seasonal Impact}

As the currents in Indian Ocean are highly variable and seasonally reversing in nature, the monthly mean estimations during $2007-2020$ of $\tau_{\text {no-Cur }}$ and $\tau_{\text {Cur }}$ fields are estimated and the difference between the two $\left(\tau_{\text {no-Cur }}-\tau_{\text {Cur }}\right)$ are shown in Figure 3. The apparent seasonal variations of the near surface currents in the Indian Ocean can be clearly seen in the monthly mean wind stress differences. Seasonal pattern of both Somali Currents and Equatorial Currents are captured in the monthly maps of the wind stress difference. The difference is prominent along the regions of stronger currents such as Somali Currents, Equatorial Jets, and Aghulhas retroflection regime. In the Somali Current regime, large difference in wind stress is observed during summer monsoon months when the current speeds are maximum climatologically. Along the equator, the wind speed differences are maximum during March-April-May and November-December during which the equatorial jets are stronger. The maximum wind stress difference occurs during fall inter-monsoon season when equatorial jets are stronger than during spring inter-monsoon season. The region south of Sri Lanka also show higher wind stress difference due to the stronger summer monsoon currents which prevails during June-September. It is seen that wind stress pattern strongly bear the signatures of the strongest currents and its seasonality, thus corroborating the strong influence of currents in modulating the wind stress. Kelly et al., 2011 reported that the signatures of surface currents are observed in the scatterometer wind data in the Pacific Ocean. The seasonal pattern of the differences between the $\tau_{\text {no-Cur }}$ and $\tau_{\text {Cur }}$ fields (Figure 4) shows that the larger deviation between the two occurs during the summer monsoon season (July-September) and the minimal deviation during the spring season (April-May). The comparison shows that significant differences exist between the wind stress fields on seasonal and monthly scales. Thus, it could be concluded that the influence of currents should be incorporated when we estimate wind stress from scatterometer 
observations.

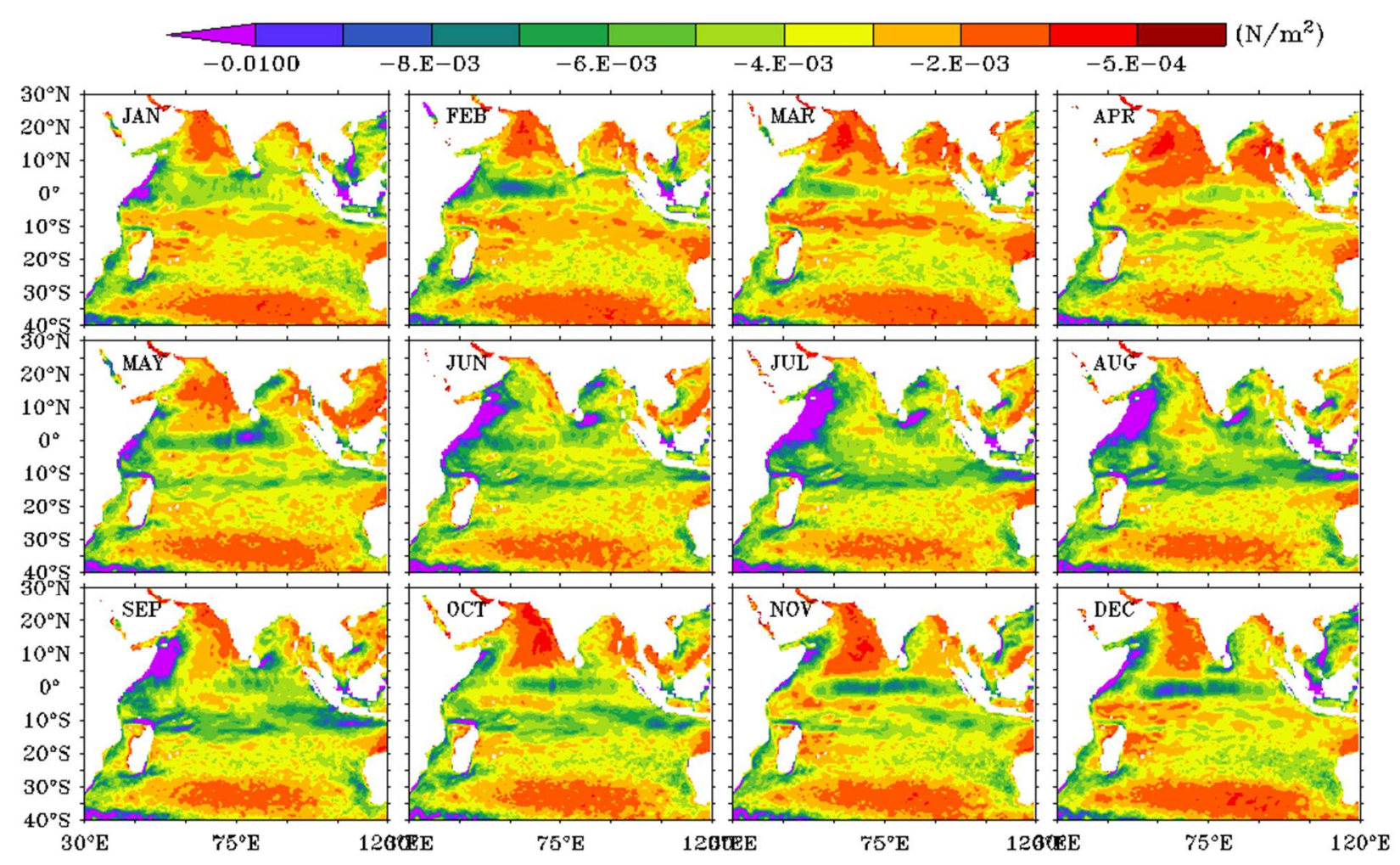

Figure 3. Monthly spatial variation of the difference between two wind stress estimations ( $\left.\tau_{\text {Cur- }} \tau_{\text {no-Cur }}\right)$ averaged over 2007-2020. 


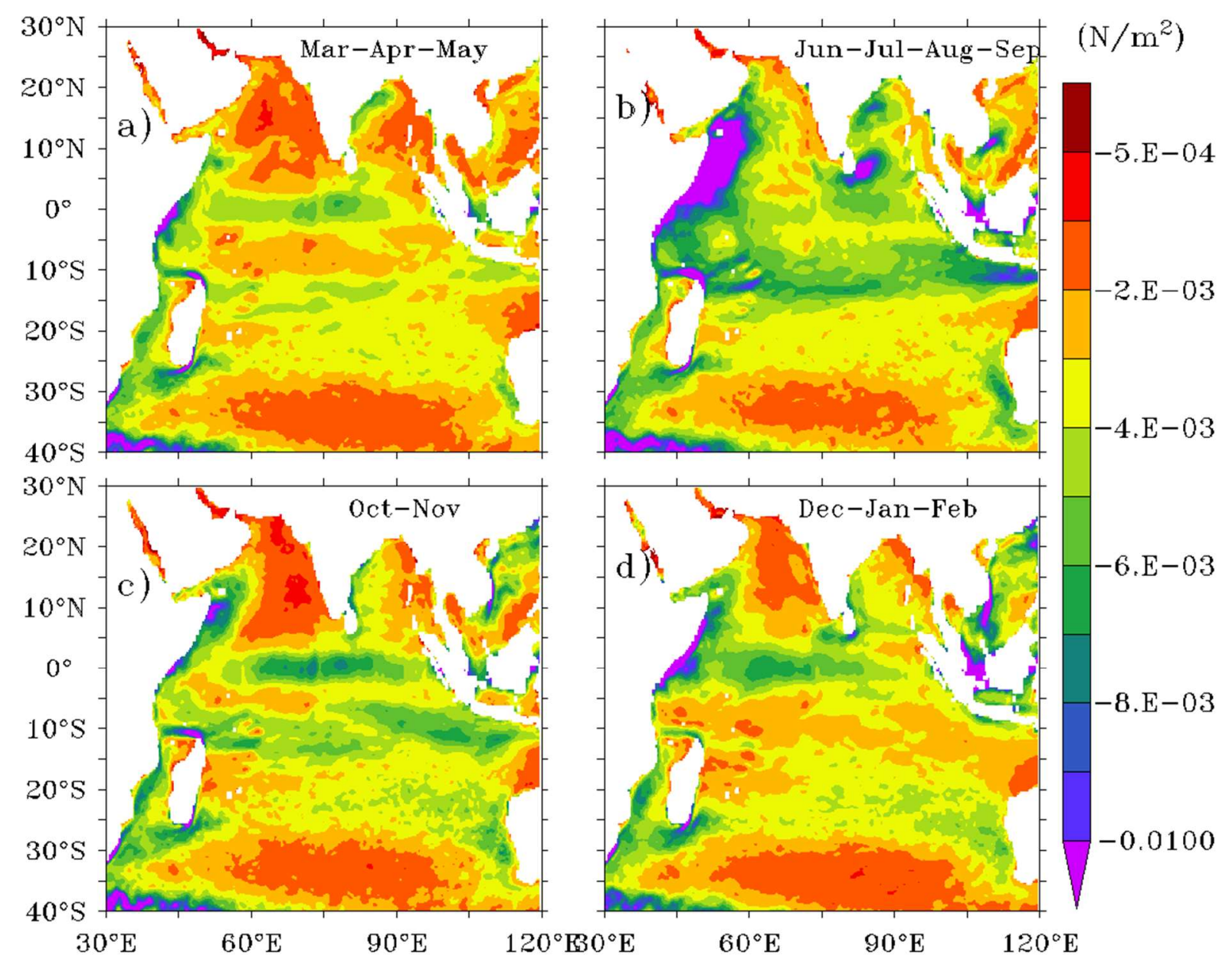

Figure 4. Seasonal and spatial distribution of the difference between the two wind stress estimations $\left(\tau_{\text {Cur }}-\tau_{\text {no-Cur }}\right)$ averaged over $2007-2020$.

\subsection{Sensitivity analysis}

It is seen from the Figures $\mathbf{1}$ - $\mathbf{4}$ that the reduction in wind stress when the surface currents are included is not uniform spatially and temporally. Hence, a sensitivity analysis has been carried out in the study region for different seasons to assess the relative impact of winds and currents in the estimation of wind stress by changing the winds while keeping the currents constant and vice versa. The exercise is done to assess how the difference in wind stress estimates is sensitive to the changes in winds and current speeds. The details of the sensitivity analysis are given in the methods section. The wind stress differences $\left(\tau_{\text {Cur }}-\tau_{\text {no-Cur }}\right)$ for each sensitivity analysis averaged over the whole 
study region $\left(30^{\circ} \mathrm{E}-120^{\circ} \mathrm{E} ; 40^{\circ} \mathrm{S}-30^{\circ} \mathrm{N}\right)$, off Somali Coast $\left(43^{\circ} \mathrm{E}-64^{\circ} \mathrm{E} ; 0-15^{\circ} \mathrm{N}\right)$, and the equatorial region $\left(60^{\circ} \mathrm{E}-90^{\circ} \mathrm{E} ; 2^{\circ} \mathrm{S}-2^{\circ} \mathrm{N}\right)$ over the study period $2007-2020$ is summarized in Table 2 . The seasonal wind stress differences between the no-currents and with currents $\left(\tau_{\text {Cur }}-\tau_{\text {no-Cur }}\right)$ are always negative for the three locations (Table 2) indicating that stress without incorporating currents is always more than that with currents. The first column in the table (EXP1_W10) is by increasing the winds by $10 \%$, the second column (EXP1_W5) is by increasing the winds by $5 \%$ without changing the currents. The third column (NOEXP) represents the differences without changing either the currents or the winds. The fourth and the fifth column (EXP2_C5 and EXP2_C10) provide the differences by increasing the currents by $5 \%$ and $10 \%$, respectively.

Compared to the NOEXP value, the differences are more when the wind speeds are increased by $5 \%$ compared to those when increased by $10 \%$. This indicates that the effect of currents is less for higher wind speeds as the higher winds dominate over the currents on the wind stress. This is true for all seasons and the three areas studied. On the contrary, the wind stress difference increases when the current speeds are increased. These results are alarming as the ocean modelers use the scatterometer derived wind speeds directly in the models without applying the correction for currents. It is suggested to use at least the climatological current speeds to the scatterometer derived wind stress. The impact of currents is highest during December-May in the Somali region when the currents speeds are low. 
Table 2. Percentage change in wind stress when surface currents are accounted in the bulk wind stress equation computed from $\tau_{\text {Cur }}$ and $\tau_{\text {no-Cur }}$ for for each sensitivity tests

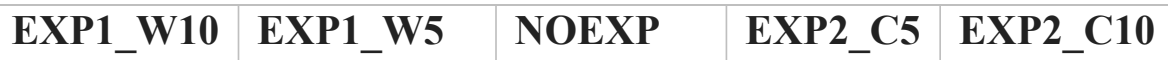

\begin{tabular}{|c|c|c|c|c|c|}
\hline \multicolumn{6}{|l|}{ Basin Averaged } \\
\hline March-April-May & $-5.279 \%$ & $-5.526 \%$ & $-5.798 \%$ & $-6 \%$ & $-11.2 \%$ \\
\hline June-September & $-4.88 \%$ & $-5.508 \%$ & $-5.3318 \%$ & $-5.59 \%$ & $-9.83 \%$ \\
\hline October-November & $-5.71 \%$ & $-5.98 \%$ & $-6.28 \%$ & $-6.562 \%$ & $-15.4 \%$ \\
\hline $\begin{array}{l}\text { December-January- } \\
\text { February }\end{array}$ & $-5.896 \%$ & $-6.159 \%$ & $-6.611 \%$ & $-6.755 \%$ & $-9.8 \%$ \\
\hline \multicolumn{6}{|l|}{ Off Somali Coast } \\
\hline March-April-May & $-16.11 \%$ & $-16.8 \%$ & $-17 \%$ & $-18.43 \%$ & $-19.22 \%$ \\
\hline June-September & $-12.04 \%$ & $-12.55 \%$ & $-13.15 \%$ & $-13.76 \%$ & $-14.39 \%$ \\
\hline October-November & $-15.46 \%$ & $-16.1 \%$ & -16.9 & $-17.6 \%$ & $-18.45 \%$ \\
\hline $\begin{array}{l}\text { December-January- } \\
\text { February }\end{array}$ & $-16.48 \%$ & $-17.2 \%$ & -18 & $-18.85 \%$ & $-19.669 \%$ \\
\hline \multicolumn{6}{|l|}{ Equatorial Region } \\
\hline March-April-May & $-9.357 \%$ & $-9.78 \%$ & $-10.24 \%$ & $-10.7 \%$ & $-11.22 \%$ \\
\hline June-September & $-8.155 \%$ & $-8.6 \%$ & $-8.9 \%$ & $-9.4 \%$ & $-9.9 \%$ \\
\hline October-November & $-13.01 \%$ & $-13.59 \%$ & $-14.18 \%$ & $-14.83 \%$ & $-15.484 \%$ \\
\hline $\begin{array}{l}\text { December-January- } \\
\text { February }\end{array}$ & $-8.2 \%$ & $-8.60 \%$ & $-8.9 \%$ & $-9.4 \%$ & $-9.8 \%$ \\
\hline
\end{tabular}

\subsection{Impact on derived parameters}

Since the ocean surface current can affect wind stress as shown in the above section, the processes which are based on wind stress also will be affected. The resultant change in the wind stress also tend to modify the wind stress derivative fields such as wind power input, Ekman currents, 
upwelling velocity, and wind stress curl (Duhaut and Straube, 2006; Shi and Bourassa; 2019). Hence, we tried to assess the impact of currents on these three major parameters: wind stress curl, Ekman Currents, and wind power input into the ocean.

The curl of the wind stress is computed using the equation,

$$
\text { curl }=\left(\frac{\partial \tau_{y}}{\partial x}-\frac{\partial \tau_{x}}{\partial y}\right)
$$

where $\mathrm{x}$ and $\mathrm{y}$ are eastward and northward coordinates and $\tau_{\mathrm{x}}$ and $\tau_{\mathrm{y}}$ the corresponding components of the wind stress. Wind stress curls are estimated using $\tau_{\text {no-Cur }}$ and $\tau_{\text {Cur }}$ and the difference between the two is illustrated in Figure 5 on an annual basis. On large scales, the wind stress curl field over much of the Indian Ocean is very similar in $\tau_{\text {no-Cur }}$ and $\tau_{\text {Cur }}$ estimations. The inclusion of surface current feedback modulates the wind stress curl more along the equatorial Indian Ocean, Somali region, coastal region along the Southwest Arabian Sea etc. The largest difference in the wind stress curl is exhibited along the equatorial Indian Ocean and the Somali region which are the permanent upwelling systems in the Indian Ocean (Schott, 1993; Schott et al., 2002). A maximum positive difference is present in the Somali and the western Equatorial Indian Ocean while the least was present in the central Equatorial Indian Ocean.

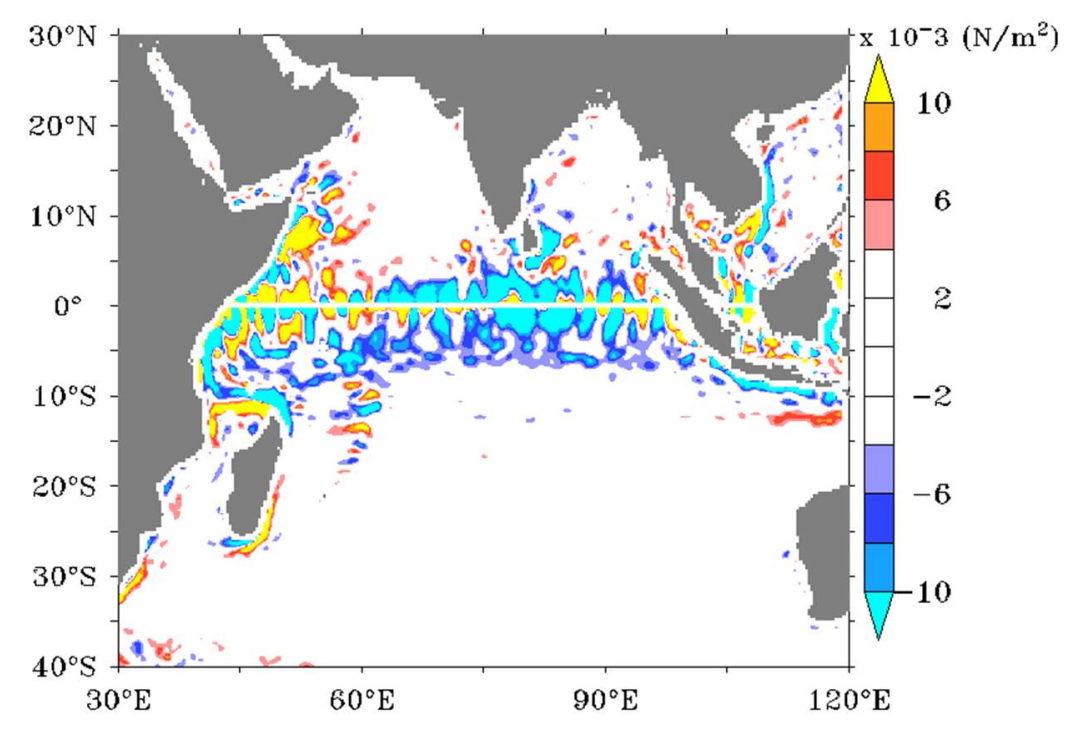


Figure 5. Average annual difference between the wind stress curl estimated with and without the inclusion of surface currents $\left(\tau_{\text {Cur }}-\tau_{\text {no-Cur }}\right)$ during 2007-2020.

Ekman current is another important field which is dependent on wind stress. Changes in the wind stress and its curl can alter Ekman currents. To show this we have calculated Ekman currents with and without surface current using the equation, Ekman Current,

$$
\mathrm{U}_{\mathrm{e}}=\frac{\tau}{\rho(A|f|)^{1 / 2}}
$$

where $\tau$ is the wind stress computed without and with the inclusion of surface currents using equations (1) and (2) respectively. The difference between the two estimations of Ekman currents is shown in Figure 6. Ekman currents reduced along major portions of the region of study after incorporating current effect. The weakening of Ekman currents can be explained due to the dampening of the wind stresses when currents are included. The reduced wind stress reduces the momentum transfer across the ocean surface and hence Ekman currents dampen. The change in the Ekman Currents induced by surface currents is dominant along the tropical Indian Ocean. The maximum reduction of Ekman Current occurs along the equatorial region. Minimal impact is seen in the region south of $10^{\circ} \mathrm{S}$ except a few localised regions like Aghulhas currents. Similarly, little change is observed in the Arabian Sea and western Bay of Bengal. Reduction is also visible along the eastern coast of India. Basin average percent reduction of Ekman currents by the inclusion of surface currents is $\sim-7 \%$ (Table 3 ). 


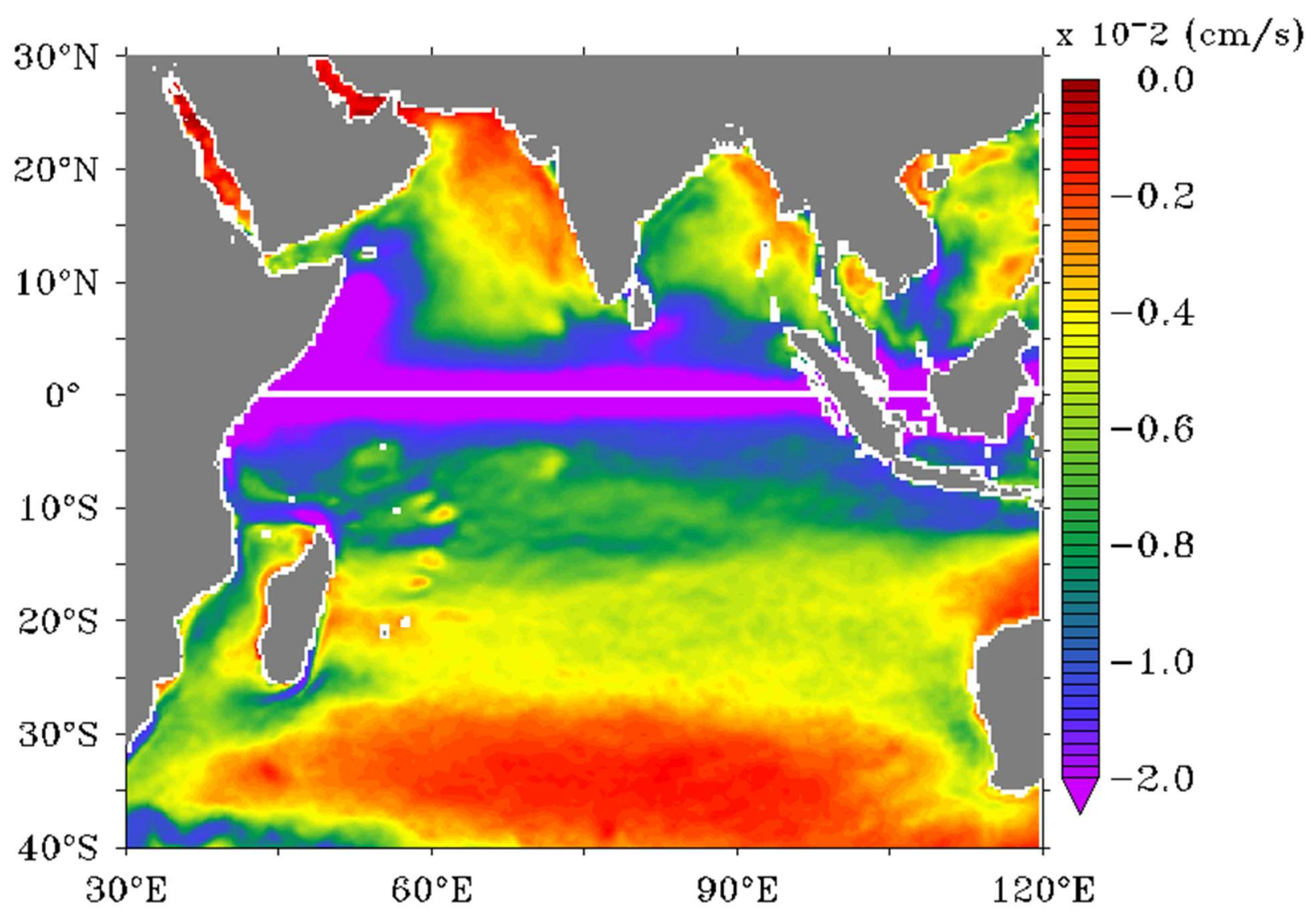

Figure 6. Average difference between the Ekman currents $(\mathrm{cm} / \mathrm{s})$ computed with and without the inclusion of currents in the wind stress during 2007-2020.

Table 3. Basin wide area averages of Ekman currents and Wind power input

\begin{tabular}{|l|l|l|l|}
\hline & $\begin{array}{l}\text { Without } \\
\text { current }\end{array}$ & With current & \% difference \\
\hline Ekman Currents $(\mathrm{m} / \mathrm{s})$ & 0.1130 & 0.1050 & -5.46 \\
\hline Wind Power input $\left(\mathrm{W} / \mathrm{m}^{2}\right)$ & 0.01110 & 0.00998 & -10.0631 \\
\hline
\end{tabular}

The ageostrophic wind power input into the ocean is estimated with and without the current inclusion using the equation

$$
\mathrm{P}=\tau * U_{e k m}
$$


where $\tau$ is the wind stress without and with the inclusion of surface currents computed using (1) and (2) respectively and $U_{\text {ekm }}$ is the Ekman Currents. The difference between the two wind powers is shown in Figure 7. The wind power input reduction is negligible throughout the Indian Ocean with an exception over the regions off Somali coast and a narrow band along the equator. An average basin wide reduction of $-10 \%$ is observed by the inclusion of surface currents in the wind stress estimation. Dave and Thompson, 2006 have reported a wind power reduction of $\sim 25 \%$ in the North Pacific Ocean.

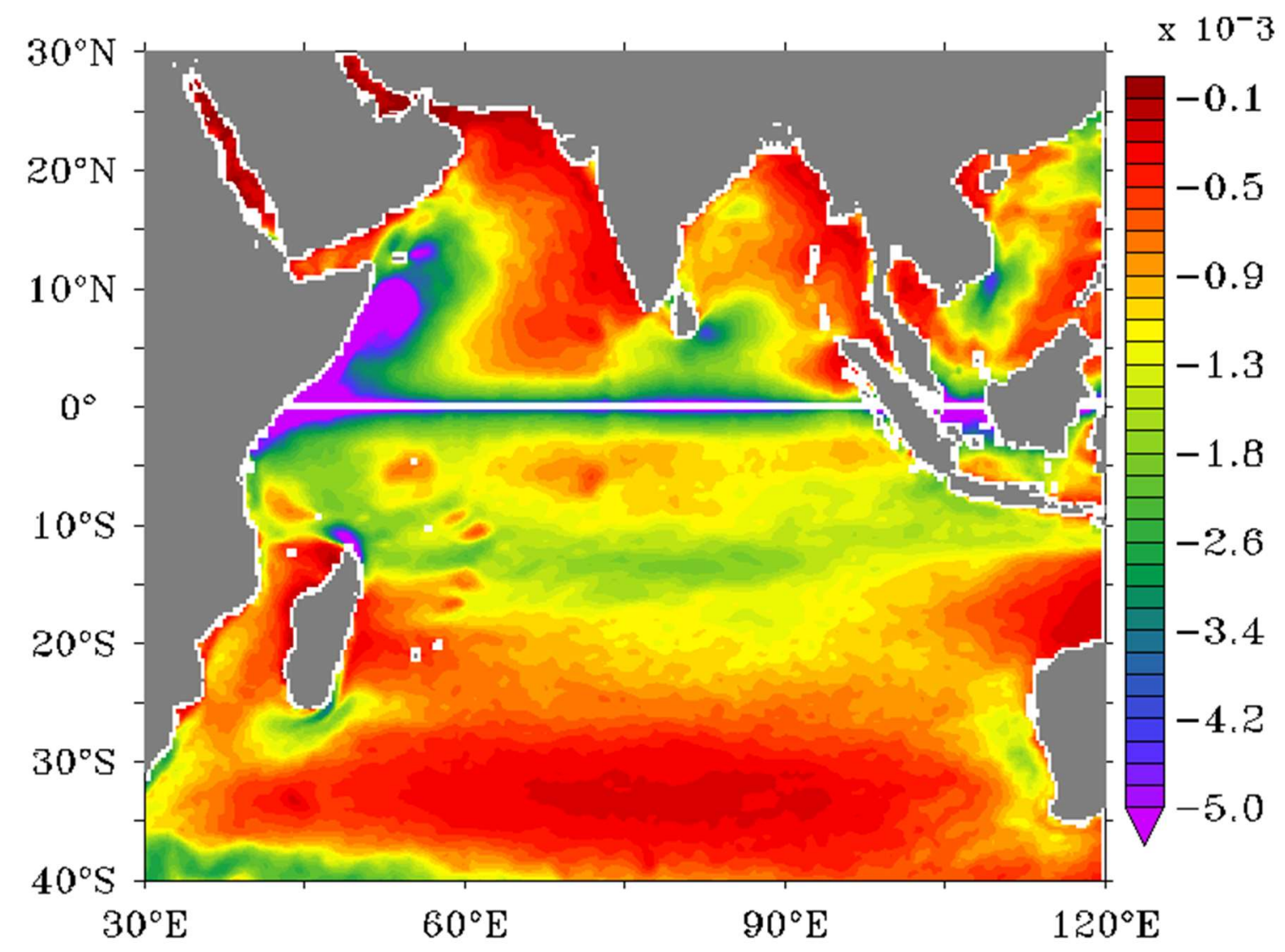

Figure 7. Average difference between ageostrophic wind power $\left(* 10^{-3} \mathrm{~W} / \mathrm{m} 2\right)$ estimated with and without the surface currents during 2007-2020. 
The inclusion of the current speed in the wind stress bulk formula resulted in the modulation of the wind stress curl, Ekman Currents and wind power input to the ocean. However, regional differences exist in the variation between each of these parameters.

\section{Conclusions}

In this work, we have assessed the impact of including surface current speeds in evaluating wind stress using bulk formula. Using thirteen years of satellite measurements of wind speeds and surface current observations, we find that currents can have a significant impact on the wind stress estimation. A basin wide reduction in the wind stress is observed when surface currents are included in the wind stress equations. While the basin averaged net wind stress reduction accounts to $-5.8 \%$, relatively notable reduction of wind stress is observed in the regions off Somali coast ($9.56 \%)$ and equatorial region (-15.93\%). Sensitivity analysis has been carried out for the study region for different seasons to assess the relative impact of winds and currents in the estimation of wind stress by changing the winds while keeping the currents constants and vice versa. The impact of currents is more for lower wind speeds compared to the higher wind speeds indicating that the effect of currents is less for higher wind speeds as the higher winds dominate over the currents on the wind stress. This is true for all seasons and the three areas studied. On the contrary, the wind stress difference prominent for higher current speeds.

We also studied the effect of inclusion of surface currents in the Ekman Currents, wind power input and wind stress curl fields. The results show that the fields which are wind stress dependent also varies, the regional differences in the variability varies for each parameter assessed. The damping effect of surface currents are strongest along the equatorial region. In general, this work highlights the importance of inclusion of surface currents in wind stress estimation. 
Uncertainties in the wind stress estimations are quite large at regional levels and hence has important implications in the air-sea interaction. This implies that better representation of wind stress by using information on currents rather than direct scatterometer wind stress should be included in the ocean/climatic models for accurate air-sea interaction studies.

\section{Acknowledgments:}

NC greatly acknowledge the support and the encouragement provided by General Manager, RRSC-east and the Director, National Remote Sensing Centre. MMA acknowledges the support and encouragement provided at COAPS, FSU and APSDMA. The ASCAT wind data used in this work is obtained from Asia Pacific Data research Centre (APDRC; http://apdrc.soest.hawaii.edu/datadoc/ascat.php). The OSCAR surface current data is downloaded from http://apdrc.soest.hawaii.edu/las/v6/dataset?catitem=2845. The figures are generated in Ferret and Origin.

\section{Conflicts of Interest:}

The authors declare no conflict of interest.

\section{References:}

Ali, M.M; Bhat, G.S.; Long, D.G.; Bharadwaj, S.; Bourassa, M.A. Estimating wind stress at the ocean surface from scatterometer observations. IEEE Geoscience and Remote Sensing Letters 2013, 10, 1129-1132. https://doi.org/10.1109/LGRS.2012.2231937.

Ali, M.M; Bourassa, M.A; Bhowmick, S.A.; Sharma, R; Niharika, K. retrieval of wind stress at the ocean surface from Altika Measurements. IEEE Geoscience and Remote Sensing Letters 2016, 13(6), 821-825. https://doi.org/10.1109/LGRS.2016.2547969.

Bonjean, F.; Lagerloef, G.S.E. Diagnostic model and anlaysis of the surface currents in the tropical Pacific Ocean. J. Phys. Oceano. 2002, 32(10), 2938-2954. 
Chelton, D.; Schlax, M.G.; Freilich, M.H.; Milliff, R.F. Satellite measurements reveal persistent small-scale features in ocean winds. Science 2004, 303, 978-983. https://doi.org/10.1126/science.1091901.

Dave, J.T.; Thompson, J. Effect of ocean surface currents on wind stress, heat flux, and wind power input to the ocean. Geophysical Res. Lett. 2006, 33, L09604. https://doi.org/10.1029/2006GL025784.

Duhaut, T.H.A.; Straub, D.N. Wind stress dependence on ocean surface velocity: Implications for mechanical energy input to ocean circulation. J. Phys. Oceanogr. 2006, 36, 202-211.

Kelly, K.A.; Dickinson, S.; McPhaden, M.J.; Johnson, G.C. Ocean Currents Evident in Satellite Wind Data. Geophysical Research Letters 2001, 28(12), 2469-2472. https://doi.org/10.1029/2000GL012610

Kloe, J. D.; Stoffelen A.; Verhoef, A. Improved use of scatterometer measurements by using stress-equivalent reference winds, IEEE JSTARS 2017, 10(5), 2340-2347. https://doi.org/10.1109/JSTARS.2017.2685242.

Luo, J.J.; Masson, S.; Roeckner, E. et al. Reducing climatology bias in an ocean-atmosphere CGCM with improved coupling physics. J. Clim. 2005, 18, 2344-2360.

O'Neill, L.W.; Chelton, D.B.; Esbensen, S.K. Covariability of surface wind and stress responses to sea surface temperature fronts, Journal of Climate 2012, 25, 5916-5942. https://doi.org/10.1175/JCLI-D-11-00230.1.

Pacanowski, R.C. Effect of equatorial currents on surface stress. J. Phys. Oceanogr. 1987. 17, 833838.

Plagge, A.M; Vandemark, D; Chapron, B. Examining the impact of surface currents on satellite scatterometer and altimeter ocean winds. J. Atmos. Ocean. Tech. 2012, 29(12), 1776-1792. https://doi.org/10.1175/JTECH-D12-00017.1.

Schott, F. Monsoon response of the Somali Current and associated upwelling. Progress in Oceanography 1993, 12(3), 357-381.

Schott, F.A.; McCreary, J.P. The monsoon circulation of the Indian Ocean. Progress in Oceanography 2001, 51, 1-123.

Seo, H.; Miller, A.J.; Norris, J. R. Eddy-wind interaction in the California Current System: Dynamics and impacts. Journal of Physical Oceanography 2016, 46(2), 439-459. https://doi.org/10.1175/JPO-D-15-0086.1.

Seo, H. Distinct Influence of Air-Sea Interactions Mediated by Mesoscale Sea Surface Temperature and Surface Current in the Arabian Sea. J. Clim. 2017, 30, 8062. 
Seo, H.; Subramanian, A.C.; Song, H.; Chowdary, J.S. Coupled effects of ocean current on wind stress in the Bay of Bengal: Eddy energetics and upper ocean stratification. Deep-Sea Research II 2019, 168, 104617. https://doi.org/10.1016/j.dsr2.2019.07.005.

Shankar, D.; Vinayachandran, P.N.; Uniikrishnan, A.S. The monsoon currents in the north Indian Ocean. Progress in Oceanography 2002, 52, 63-120. https://doi.org/10.1016/S0079$\underline{6611(02) 00024-1 z}$.

Shenoi, S.S.C.; saji, P.K.; Almeida, A.M. Near-surface circulation and kinetic energy in the tropical Indian Ocean derived from Lagrangian drifters. Journal of Marine Research 1999, 57, 885-907.

Shi, Q.; Bourassa, M.A. Coupling ocean currents and waves with wind tress over the Gulf Stream. Remote Sensing 2019, 11, 1476; https://doi.org/10.3390/rs11121476.

Song, H.; Marshall, J.; McGillicuddy, D. J.; Seo, H. Impact of current-wind interaction on vertical processes in the Southern Ocean. J. Geophys. Res.: Oceans 2020, 125, e2020JC016046. https://doi.org/10.1029/2020JC016046.

Swallow, J.C.; Bruce, J.G. Current measurements off the Somali Coast during southwest monsoon of 1964. Deep-Sea Res. 1966, 13, 861-888, https://doi.org10.1016/0011-7471(76)90908-6.

Wyrtki, K. An equatorial jet in the Indian Ocean. Science, 1973. 181, 262-264. 